\title{
EXPLORING THE IMPACTS OF INDUSTRY 4.0 FROM A MACROSCOPIC PERSPECTIVE
}

\author{
Zhou, Rongyan; Le Cardinal, Julie \\ Laboratoire Génie Industriel, CentraleSupélec, Université Paris-Saclay
}

\begin{abstract}
Industry 4.0 is a great opportunity and a great challenge for enterprises. Nowadays, how to adjust the strategy according to the new situation to deal with the opportunities and challenges brought by Industry 4.0 is a hot topic. The paper investigates what is Industry 4.0 and compares the different fourth industry revolution programs in various countries and takes advantage of bibliometric to investigate which technologies play an important role in Industry 4.0. What is more, the status quo, challenges and development directions faced in various fields in the industrial 4.0 era are elaborated. The paper not only combs the research direction for researchers, but also presents the status quo of practical application for enterprises. The paper contributes to showing a leading role for theory and practice of industry 4.0.
\end{abstract}

Keywords: Industry 4.0, Big data, Market implications

\section{Contact:}

Zhou, Rongyan

CentraleSupélec, Université Paris-Saclay

Industrial Engineering Research Department(LGI)

France

rongyan.zhou@centralesupelec.fr 


\section{INTRODUCTION}

The "Industrial 4.0" concept appeared first in an article published by the German government in November 2011, as a high-tech strategy for 2020 (Zhou, 2015). However, Industry 4.0 is an emerging and large topic. What impact will Industry 4.0 bring, how companies and organizations deal with Industry 4.0 technologies, and what is the current status of research and practical application of Industry 4.0? The above issues concerned by scholars and enterprises are also the focus of this paper. Some scholars have conducted research on Industry 4.0. in literature research of Industry 4.0, (Colantoni et al., 2019) summarized the current situation and development prospects of agriculture in the context of Industry 4.0. (Lezzi et al., 2018) sorted out the literature on industrial 4.0 cybersecurity. (Ding, 2018) analysed the literature in sustainable pharmaceutical supply chains. (Dallasega et al., 2018) investigated how industry enable to construction supply chains. (Li et al., 2015) surveyed the researches of industrial wireless networks in the context of Industry 4.0. (Krejcar et al., 2018) used literature surveys to tidy up the possible consequences of Industry 4.0 for the economy and business. Most of these articles focus on a microscopic perspective to conduct literature research. Of course, there are also a few articles that analyse the industry 4.0 literature from a macro perspective. For example, (Lu, 2017) carried out a statistical classification of the technologies involved in the Industry 4.0 literature. (Pereira et al., 2018) only conducted statistical analysis of the Industrial 4.0 literature from 2011 to 2017. (Piccarozzi et al., 2018) analysed the literature related to Industry 4.0 in the past five years, but the analysis also focused on literature statistics. Although the article also summarized other literatures, it did not show detailed development directions and specific practical status.

Therefore, we can see from the above that the literature review for Industry 4.0 in the past mostly focused on microscopic perspectives to summarize and analyse a certain field or certain technologies. A few articles that analyse Industry 4.0 from a macro perspective focus mostly on bibliometric analysis, although these articles summarize the content of the literature but lack practical guidance for real-world businesses and research. This paper not only uses literature analysis to sort out the literature, but also focuses on the use of "core literature extension method" to enumerate the development direction and application status of different fields. This paper not only combs the research direction for researchers, but also shows the status quo of practical application for enterprises. The paper devotes to showing a leading role for theory and practice of industry 4.0.

\section{METHODOLOGY}

This study adopts bibliometric and "core literature extension method" based on systematic literature review approach with the aim to explore the impact of industry 4.0 from a macroscopic perspective. As shown in the Figure 1, our research is mainly divided into three steps, first of all to look into what is Industry 4.0; secondly to identify the core technology of Industry 4.0; thirdly investigate industry 4.0 research status and practice status.

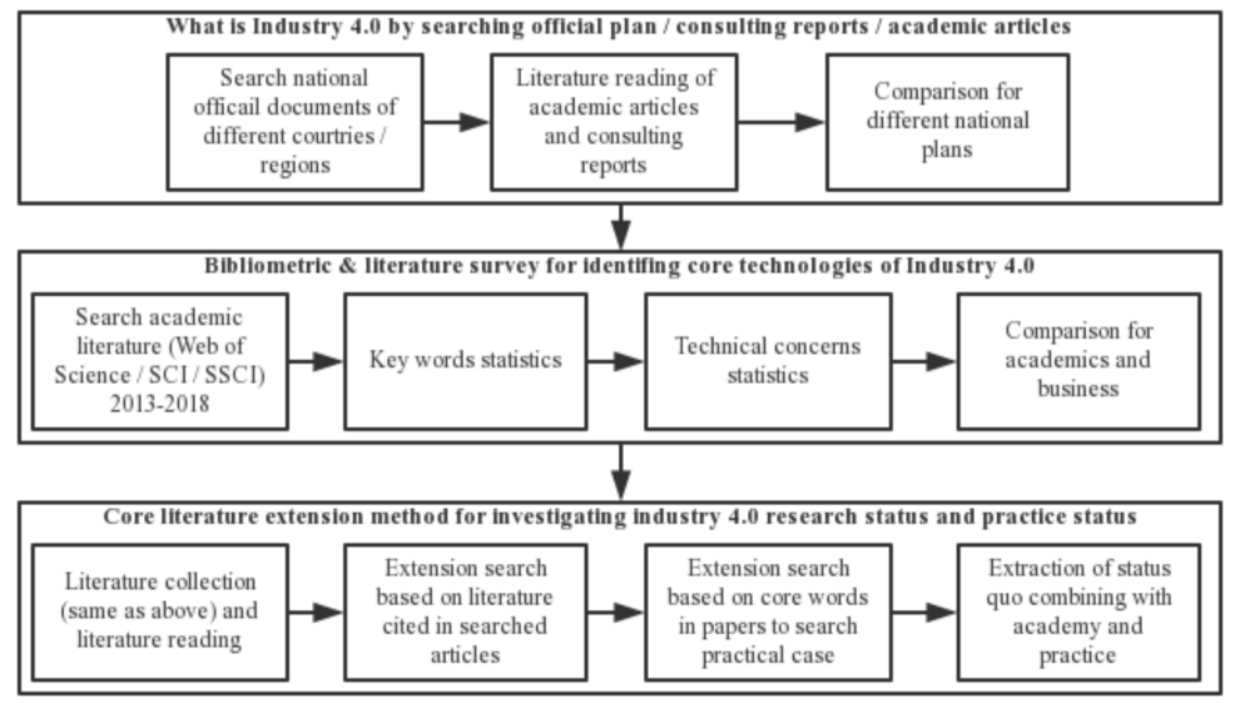

Figure 1. Research methodology 
In first step, although such as (Piccarozzi et al., 2018)(Piccarozzi et al., 2018) have investigated the concept of Industry 4.0 in their articles, few articles have compared and surveyed the fourth industrial revolution plan of different countries. In this part, our study not only collates the concept of Industry 4.0 appearing in academic articles, but also analyses the official planning documents of various countries and famous consulting companies' reports to compare different fourth industry revolution plans. In the second step, we searched for articles with the words of "industry 4.0" and "industrie 4.0" in the title and that were retrieved by Science Citation Index Expanded (SCI-EXPANDED) and Social Sciences Citation Index (SSCI) from 2013 to 2018 searched by Web of Science based on bibliometric. It should be noted that the reason why our study starts to collect literatures from 2013 is because there is no article before 2013 under our search framework. In the third part, we present the status quo of academy and practice as well as future opportunities and challenges based on core literature extension method.

\section{WHAT IS INDUSTRY 4.0}

In 2012, the German government passed the 'High-Tech Strategy 2020' action plan, which annually sets billions of euros aside for the development of cutting-edge technologies (Bunse, 2013). The fourth industrial revolution has become the focus of public attention. Similarly, other countries have also put forward the corresponding fourth industrial revolution plan. France (Economie.gouv.fr, 2015) proposed Industrie du Futur that formulated nine key development solutions: data economy; smart objects; digital trust; smart power; new resources; sustainable city; ecological mobility; future medicine; future transport. The United States (The White House, 2011) launched the Advanced Manufacturing Partnership (AMP) and the Industrial Internet Consortium (IIC) led by General Electric was established. United Kingdom (UK) (Department for Business Energy and Industrial Strategy (BEIS) of UK, 2013) launched Future of Manufacturing. China (State Council of the People's Republic of China, 2015) put forward "Made in China 2025", which aims to enhance the competitiveness of Chinese manufacturing and accelerate the industrial upgrading of China's manufacturing industry. In report of (Jan SMIT, Stephan KREUTZER, Carolin MOELLER, 2016) to the European Parliament, which gave the main features of Industry 4.0: interoperability, virtualization, decentralization, real-time capability, service orientation and modularity.

Most countries in the world have launched relevant plans according to their own national conditions. Here are just a few representative manufacturing powers, others are not listed one by one. Among them, the concept of Industry 4.0 proposed by Germany and the concept of Industrial Internet in the United States are the most widely spread. By understanding the industrial plans of European countries, most European countries' plan closer to the German's Industry 4.0 program. Next, combining the scientific articles and consulting reports and official documents obtained from the search framework that we mentioned in part of methodology, we compare the fourth industrial revolution plans of the world's top three economies, the EU, the US and China.

The concept of Industry 4.0 focus on the interaction of production side. Based on strong industrial base, it integrates information and communication technologies, and aims to build smart factory and intelligent production. The focus is on creating smart products and processes that place greater emphasis on Internet of Things (IoT) and control logic. To a certain degree, Industry 4.0 hopes to reduce labour costs through intelligentialize. It can also be said that Industry 4.0 is a top-down reform, which means the manufacturing industry pull the information industry.

The US-led "industrial Internet" and "Advanced Manufacturing Partnership" pay more attention to the client's big data. Based on a highly developed information technology, according to big data information flow analysis, decision-making, to carry out intelligent manufacturing. Its elements are smart devices, intelligent networks and decision-making, and emphasis more on sensor systems, big data analytics capabilities. Put another way, US-led plan is a bottom-up reform, which means the information industry pull the manufacturing industry.

The China Manufacturing 2025 program is more suitable for countries with a late start of industrialization, which emphasizes the parallel development of manufacturing and information industries, emphasizing the integration and Internet plus. In the process of the fourth industrial revolution, China also needs to face the irrational industrial structure brought about by imperfect third industrial revolution. This leapfrog development plan is a good reference for developing countries.

The survey contributes to enhancing the understanding of scholars and practitioners on policy orientation in different regions so that they can take less detours. Although the different plans are 
different in detail according to their national conditions, there is still a lot of similarities in most of the content. This paper uses Industry 4.0 to denote the generalized fourth industrial revolution.

\section{BIBLIOMETRIC SURVEY FOR CORE TECHNOLOGIES OF INDUSTRY 4.0}

Search for articles on the Web of Science with Industry 4.0 or Industrie 4.0 in articles' title retrieved by Science Citation Index Expanded (SCI-EXPANDED) and Social Sciences Citation Index (SSCI) from 2013 to 2018 . We set the search frame to obtain articles that are more relevant to the topic and to get high quality articles to improve the quality of the information we get. We did not find articles before 2013 under the search frame, so we analysed the articles from 2013-2018. A total of 282 articles were retrieved, the specific number and trend shown in Figure 2. Among them, 272 were indexed by SCI and 69 by SSCI.

It can be seen from Figure 2 that theme of Industry 4.0 has become more and more hot topic in recent years. We then performed statistics for the keywords of all the articles we searched. What needs to be explained here is that we only count the author keywords and do not count the key words plus. We believe that the author keywords are more in line with the subject of the article. The statistical results are shown in Figure 3. Except "Industry 4.0", the three most frequently cited keywords are: Internet of Things (IoT), Cyber-Physical Systems (CPS) / (CPSs) and Big Data.

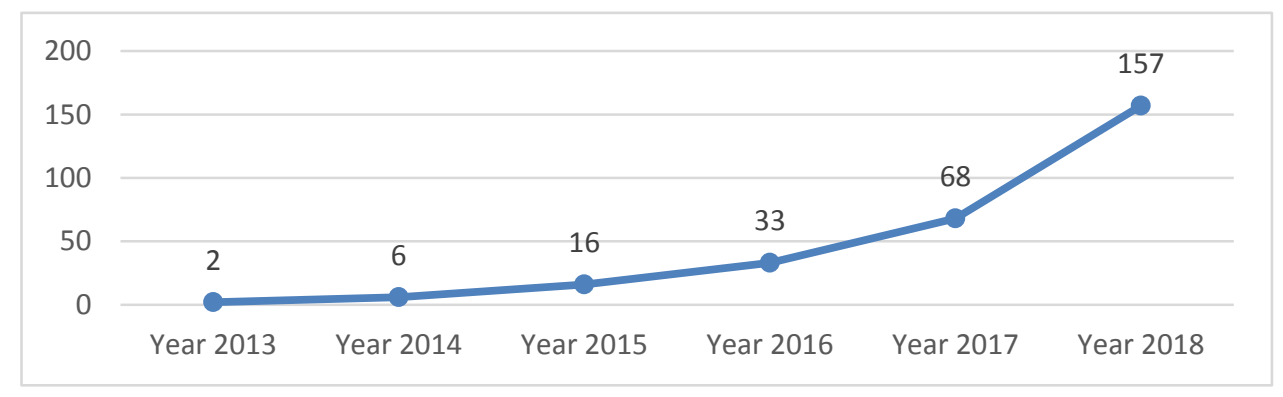

Figure 2. Literature statistics

As can be seen from the Figure 3, Internet of Things (IoT) is the most frequently mentioned in these articles, followed by Cyber-Physical Systems (CPS) and again for the Big Data. And it can be seen that the number of Internet of Things (IoT) mentioned in 2018 has suddenly increased. That is to say, in the topic of Industry 4.0, big data, CPS and Internet of Things are the most popular components of Industry 4.0 in academic fields, which may also means that they are the most important cores component for industry 4.0.

In addition, since the frequency of the top three keywords in the keyword statistics is much higher than other keywords, only the three keywords with the highest frequency are listed in Figure 3. Cloud computing and additive manufacturing also were mentioned many times and ranked fourth and fifth. Then we studied the consulting reports of well-known consulting companies with higher practical value.

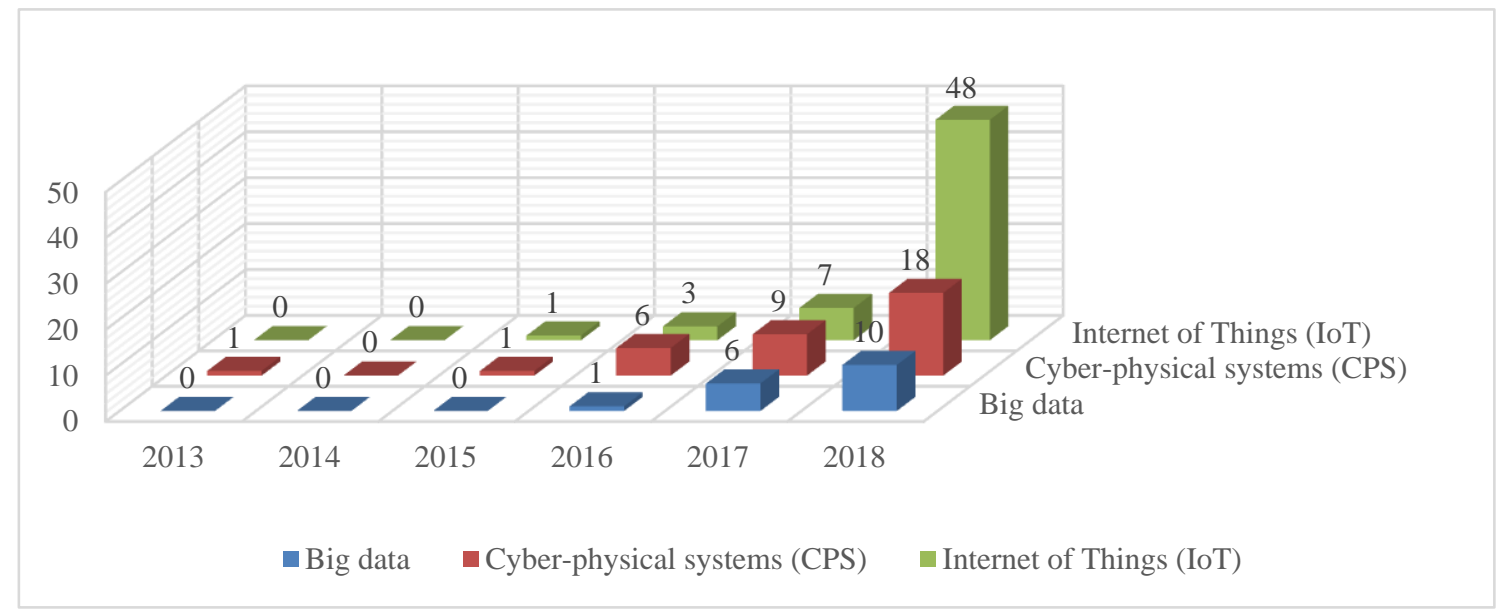

Figure 3. Keyword statistics 
We surveyed 50 consulting companies listed according to the "Vault Consulting 50". We found 19 of them with reports specifically for the fourth industrial revolution. Other companies also mentioned the fourth industrial revolution but they did not publish detailed reports.

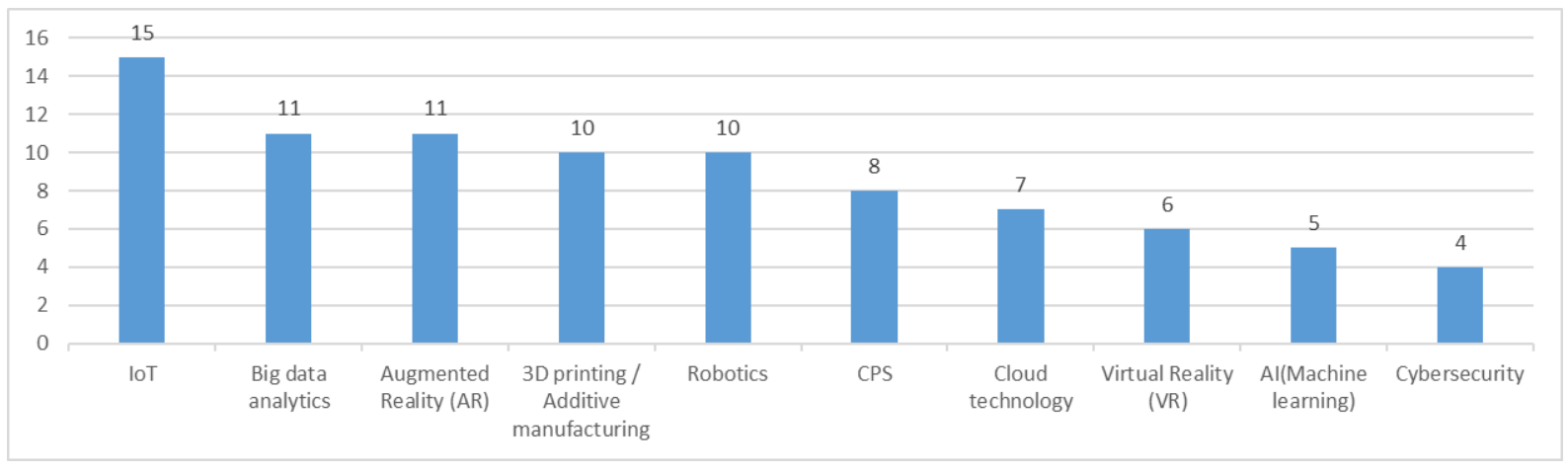

Figure 4. Technical concerns statistics

Figure 4 shows the statistics of the technology concerns in the report of 19 companies for Industry 4.0. The technical concerns mentioned in the statistics refer to the techniques that are separately segmented and focused on in the report. Here are the ten most watched technologies.

In these consulting reports, (McKinsey \& Company, 2015) (OliverWyman, 2016) and (Beducker et al., 2017) concentrated on digitization of the manufacturing sector; (Rüßmann et al., 2016) focused on future productivity and manufacturing prospects; (RolandBerger, 2015) (Vardhan Singh and Berger, 2014) (Lindstrom, 2017) (CGI, 2017) and (Cotteleer and Sniderman, 2017) made a macroscopic analysis for economic, social and industrial model; (Reinhard Geissbauer, Jesper Vedso, 2016) (Schreiber et al., 2016) and (EY, 2018) were occupied with building the digital enterprise; (Jain et al., 2017) carried out a CEO's view to analyse industry 4.0; (Harris et al., 2018) shown a technological frame; (Goddard et al., 2015) specially analyse IoT; (Barbier, 2017) (Schenkel, 2016) and (Tratz-Ryan et al., 2018) presented the trends and opportunities for industry 4.0; (Kiesau et al., 2015) analysed the impacts in healthcare fields.

It can be seen that both academic articles and consulting reports refer to big data and the Internet of Things at the most, but the proportion of CPS mentioned in the consulting report is lower than in academic articles. In addition, the proportion of augmented reality (AR), 3D printing / additive manufacturing and robotics in the consulting report is higher than academic articles. The investigation aims to help scholars to further understand market development needs and increase mutual understanding between academics and business.

\section{IMPACTS ON INDUSTRIAL SECTORS}

Since the concept of Industry 4.0 was first targeted at manufacturing, we summarized the research hotspots and development status of manufacturing in the context of Industry 4.0 based on the literature. Manufacturing and economic development complement each other, the financial industry is an important source of support for the manufacturing industry. So we also summarize the development direction and practice status of the economic and financial fields.

\subsection{Financial and economic sectors}

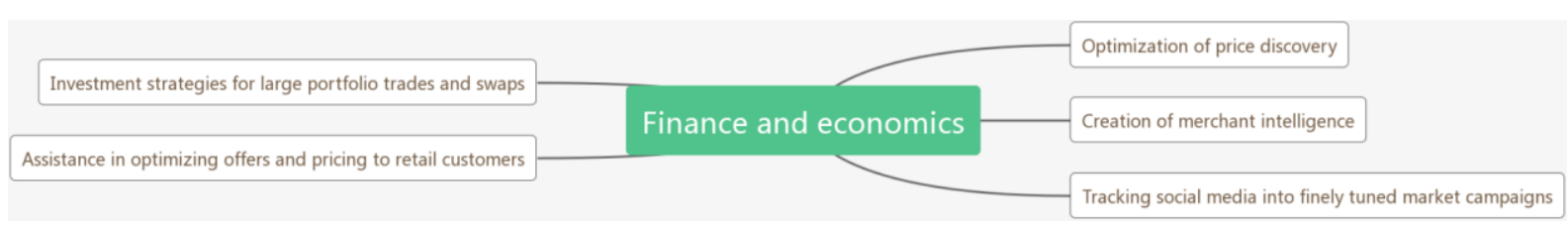

Figure 5. Status and development direction of industry 4.0 for finance and economics

In the financial and economic sectors, companies can learn more about supplier information and get more buyer information through big data, and big data will provide companies with more assessments of products or services. Enterprises can make more accurate and objective decisions based on the calculation results of quantitative data, rather than subjective decisions in the past. At the same time, 
data platforms came into being, such as Hong Kong Stock Exchange price discovery platforms (Lam, 2014). At the Third Future Industrial Conference held in Lyon in 2018, the French government and the Future Industrial Association also began to build a new price discovery platform. The consulting companies such as Ernst \& Young also launched data services related to this. Setting up an information platform to provide data services seems to be a hot area of current entrepreneurship. At the same time, whether the block chain can be applied to these platforms is also a hot topic.

In the investment field, in investment strategies for large portfolio trades and swaps, methods using machine learning and other algorithms to learn historical data and then perform existing data analysis based on historical experience have been applied in practice. Of course, the optimization of machine learning and deep learning algorithms is still in progress, which is also a hot topic in the financial field of big data. For example, (Cheng et al., 2018) used matching samples based on year, industry, and probability of future bankruptcy model to enhance the solvency prediction capabilities of recent machine learning techniques.

Creation of merchant intelligence has also been used by banks, investment companies and other companies. According to the data analysis system, it can automatically identify potential customers and customers who are carrying out untrustworthy behaviour. Headhunting companies also use similar systems to explore human resources. For example, LinkedIn's automatic recommendation system can be seen as an application of this model.(Yiming Ma, Bee-Chung Chen \& Deepak Agarwal, 2017) Tracking social media into finely tuned market campaigns has already appeared in our lives. TripAdvisor have already begun to recommend hotel and restaurant to users through user's' social media data(Valdivia et al., 2017). In the US presidential election, the campaign team using social media data to choose their own strategy can also be seen as an extension of this field.(Madanapalle, 2017)

\subsection{Manufacturing sector}

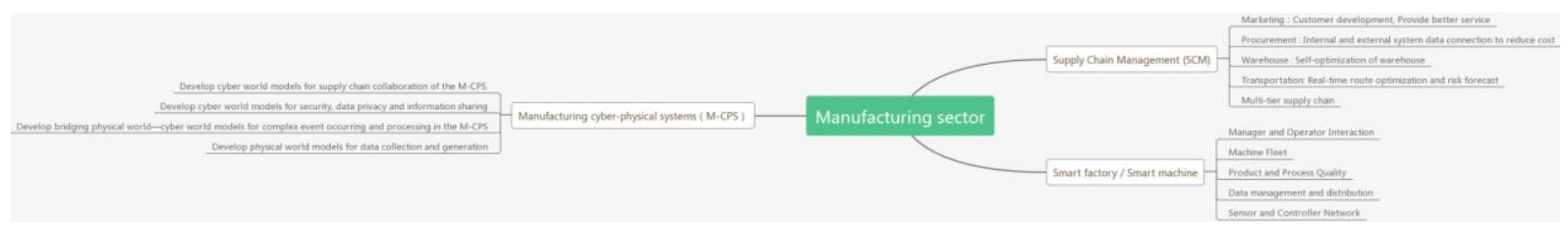

Figure 6. Status and development direction of industry 4.0 for manufacture

In the manufacturing sector, the supply chain has to be mentioned. (Varela and Tjahjono, 2014) summarized four levers in the big data driven supply chain: Marketing, Procurement, Warehouse, and Transportation.

The application of big data will have a huge impact on the supply chain. In marketing level, big data applications will better manage customer information, build better relationships with customers and gain insight into potential customers. JD is applying Big Data and Artificial Intelligence ("AI") to predict customer demands for products directly sold. Based on demand projections and real-time data on remaining inventory, automatic procurement orders are issued to upstream manufacturers to restock (Panda, 2017).

In procurement level, internal and external system data need to connect to reduce the cost. Barnes \& Noble (B\&N) (Frehe et al., 2014) use Big Data. They run a portal through which their suppliers are granted insights in their sales at B\&N without having to buy software.

Warehouse management (especially inventory management) has been radically altered by modern identification systems after the successful introduction of RFID. In warehouse management center, real-time optimization can be performed based on real-time data from IoT sensors. (Giannikas et al., 2013) show a good example that how a Warehouse Management System (WMS) using product intelligence can be beneficial for the scheduling and control of the storage location assignment and the picking operations and they argued on the significance of these benefits using a case study of a thirdparty-logistics warehouse company.

The efficiency of transportation and the ability of risk forecasting have greatly improved by big data analysis. The companies can not only select the optimal path in real time but also effectively avoid natural disasters and vehicle failures. UPS uses telepathic trucks which have sensors that capture over 200 data points for more than 80,000 vehicles every day UPS used proprietary package flow technology 
to determine what packages are loaded on each vehicle, then gathers data from several aspects of fleet operations using a telematics technology system (Singh Jain et al., 2017).

The above analysis for supply chain from a disparate perspective, and from a holistic perspective, the multi-tier supply chain is also a hot topic under the background of Industry 4.0. For instance, (Pedram et al., 2017) develops a mathematical model for a closed loop supply chain network which provides decision support to practitioners of end-of-life tire recovery as well as determines the numbers and the locations of facilities and the material flows between these facilities. Multi-tier supply chain research in the context of Industry 4.0 will also be the focus of our future research.

(Babiceanu and Seker, 2016) mentioned that develop cyber world models for all levels of the Manufacturing cyber-physical systems (M-CPS) will be a good direction in the future. (Pedone and Mezgár, 2018) showed cyber-physical systems refer to a preliminary architecture of the Reference Architectural Model Industrie (RAMI 4.0) and the Industrial Internet Reference Architecture (IIRA) virtualized and connected services/assets in GINOP Project's Manufacturing Execution and Support System.

Smart factories and smart machines are an important component of Industry 4.0 in the manufacturing sector. (Lee et al., 2014) divided fundamental issues of self-aware and self-learning machines into five distinct categories and carried out a smart remote machinery maintenance system with Komatsu. (Wan et al., 2016) proposed a software-defined IIoT architecture to manage physical devices and provide an interface for information exchange. (Ji et al., 2016) presented a heterogeneous device data ingestion model for an industrial big data platform. The model includes device templates and four strategies for data synchronization, data slicing, data splitting and data indexing, respectively. Therefore, for a manufacturing company to realize a smart factory is a system engineering, the introduction of IoT equipment, the construction of software platforms and the choice of algorithms etc. all of above will determine the performance of smart factory.

In addition, the impact of additive manufacturing on the supply chain is not reflected in the above figure. 3D printing materials reduces the need for the physical location move, the demand for warehouse also will be changed. Although the case studies show the potential impact of disruptive technology in the supply chain, but (Kothman and Faber, 2016) considered that more empirical research is needed to understand the underlying mechanisms.

This review is conducive to present the details of status of research and practice as well as broaden the horizon for scholars and practitioner.

\section{CONCLUSION}

According to BCG research, in the next decade, the increased investment in Industry 4.0 in Germany will reach 250 billion euros, although the transformation of industry 4.0 will be completely taken about 20 years. But some key advantages will gradually be established in the next 5-10 years.(Rüßmann et al., 2016) According to PwC's survey with over 2,000 participants, in 2016, there were US $\$ 493$ billion in industry 4.0 digital revenue and US $\$ 907$ billion in annual industry 4.0 digital investments.(Reinhard Geissbauer, Jesper Vedso, 2016) Therefore, the Industry 4.0 is a major historical opportunity, but also a test for enterprises.

This paper first explores what is Industry 4.0 and compares the different fourth industry revolution programs in various countries by analysing official documents, consulting reports and academic articles; then takes advantage of bibliometric to investigate which technologies play an important role in Industry 4.0. Subsequently, the status quo, challenges and development directions faced in various fields in the industrial 4.0 era are elaborated based on core literature extension method. This paper not only allows researchers to understand the status quo of research and hunt for research directions, but also can be applied to enterprises and organizations to spark inspiration and improve practice.

With regard to the research process design, in the original basic literature collect, only the articles indexed by SCI and SSCI and titled Industry 4.0 were selected, which greatly improved the search accuracy and ensured the quality of the article, which provided a good foundation for "core literature extension research". Research on official documents, consulting reports and academic literature combined with bibliometric strengthens the link between academic research and practice, makes this paper more practical and instructive, and to some extent opens up the bridge between scientific research and application. The core literature extension method guarantees the quality and advancement of indexed content by first collecting high-quality papers and then by analysing the cited articles in 
high-quality papers and the high-frequency vocabulary mentioned in them to continue searching for articles and practical cases. The research process design of the paper also provides new practical experience for literature review articles.

\section{LIMITATION AND OUTLOOK}

Although this article hopes to make a relatively comprehensive explanation, because Industry 4.0 is very broad, the paper cannot include all aspects. This article summarizes Industry 4.0 based on its own understanding by the limited materials. This article focuses on the application of Industry 4.0 in finance $\&$ economics and manufacturing sector, the research field is not comprehensive enough. In future research, we will continue the research on Industry 4.0 in more various industries and give a better classification for the industry researches. In addition, we will summarize the cutting-edge technologies and models of the industry 4.0 from a more microscopic perspective.

What is more, our future research aims to mix qualitative and quantitative methods to model and analyse new frameworks and phenomena emerging in the Industrial 4.0 era. Specifically, to analyse or model the expected contribution of Industry 4.0 technologies for industrial performance. The following research directions will be focused: multi-tier supply chain, market maturity analysis and technology roadmap; Industry 4.0 and make or buy decision (outsourcing or self-produce facing with automation and robots) and new business models support Industry 4.0.

\section{REFERENCES}

Babiceanu, R.F. and Seker, R. (2016), "Big Data and virtualization for manufacturing cyber-physical systems: A survey of the current status and future outlook", Computers in Industry, Elsevier B.V., Vol. 81, pp. $128-137$.

Barbier, F. (2017), 5 “Trends For The Future Of Manufacturing”, available at: https://www.ge.com/reports/5trends-future-manufacturing/ (accessed 13 March 2019).

Beducker, T., Bokeria, G. and Frahm, M. (2017), Digitalization in the Industrial Sector, available at: https://www.simon-kucher.com/en/blog/digitalization-industrial-sector (accessed 13 March 2019).

Bunse, B. (2013), "Industrie 4.0- Smart Manufacturing for the Future", GTIA- Germany Trade and Invest, p. 40.

CGI. (2017), "Making Your Business More Competitive", CGI GROUP INC.

Cheng, C., Jones, S. and Moser, W.J. (2018), “Abnormal trading behavior of specific types of shareholders before US firm bankruptcy and its implications for firm bankruptcy prediction", Journal of Business Finance and Accounting, John Wiley \& Sons, Ltd (10.1111), Vol. 45 No. 9-10, pp. 1100-1138.

Colantoni, A., Cecchini, M., Egidi, G., Saporito, M.G. and Zambon, I. (2019), "Revolution 4.0: Industry vs. Agriculture in a Future Development for SMEs", Processes, Multidisciplinary Digital Publishing Institute, Vol. 7 No. 1, p. 36.

Cotteleer, M.M. and Sniderman, B. (2017), "Forces of Change: Industry 4.0”, Deloitte Insights, available at: https://doi.org/10.1007/s11947-009-0181-3.

Dallasega, P., Rauch, E. and Linder, C. (2018), "Industry 4.0 as an enabler of proximity for construction supply chains: A systematic literature review", Computers in Industry.

Department for Business Energy and Industrial Strategy (BEIS) of UK. (2013), "Future of manufacturing: a new era of opportunity and challenge for the UK - summary report", available at:

https://www.gov.uk/government/publications/future-of-manufacturing/future-of-manufacturing-a-new-eraof-opportunity-and-challenge-for-the-uk-summary-report\#conclusions.

Ding, B. (2018), "Pharma Industry 4.0: Literature review and research opportunities in sustainable pharmaceutical supply chains", Process Safety and Environmental Protection, Elsevier, Vol. 119, pp. 115-130.

Economie.gouv.fr. (2015), "L’Industrie du Futur”, Economie.Gouv.Fr.

EY. (2018), "Industry 4.0: Engaging with Disruption Enterprise IT Trends and Investments 2018”, available at: https://www.ey.com/Publication/vwLUAssets/ey-industry-engaging-with-disruption/\$File/ey-industryengaging-with-disruption.pdf (accessed 12 March 2019).

Frehe, V., Kleinschmidt, T. and Teuteberg, F. (2014), "Big Data in Logistics - Identifying Potentials through Literature, Case Study and Expert Interview Analyses”, INFORMATIK 2014: BIG DATA: Komplexität Meistern; 44. Jahrestagung Der Gesellschaft Für Informatik e.Vol. GI No. 2, pp. 173-186.

Giannikas, V., Lu, W., Mcfarlane, D. and Hyde, J. (2013), "Industrial Applications of Holonic and Multi-Agent Systems", Vol. 8062 No. September 2015, available at: https://doi.org/10.1007/978-3-642-40090-2.

Goddard, J., Verge, L. and Meier, P. (2015), “The Next Industrial Revolution?”, Get Ready for the Internet of Things (IoT), available at: https://www.lek.com/sites/default/files/insights/pdf-

attachments/IoT_InternetofThings_IoT-Revolution_LEK-ExecutiveInsights-1721_2.pdf (accessed 14 March 2019). 
Harris, P., Hendricks, M. and Logan, E.A. (2018), “A Reality Check for Today’s C-Sui Te on Industry 4”, 0, available at: https://assets.kpmg/content/dam/kpmg/xx/pdf/2018/11/a-reality-check-for-todays-c-suite-onindustry-4-0.pdf (accessed 12 March 2019).

Jain, P., VP, R.S., Services, E. and Mondal, T. (2017), “HfS Blueprint Guide: Industry 4.0”, Services 1 HfS Blueprint Guide: Industry 4.0 Services, available at: www.hfsresearch.com\%7Cwww.horsesforsources.com (accessed 12 March 2019).

Jan, S., Stephan K., Carolin M., M.C. (2016), "Directorate general for internal policies policy department a: economic and scientific policy", No. c, pp. 1-4.

Ji, C., Shao, Q., Sun, J., Liu, S., Pan, L., Wu, L. and Yang, C. (2016), "Device data ingestion for industrial big data platforms with a case study", Sensors (Switzerland), Vol. 16 No. 3, pp. 1-15.

Kiesau, T., Pinter, K., Schumm, A., Manager, E., Stearns, L., Graboys, K., Director, M., et al. (2015), The Chartis Group Innovation Center: Healthcare Providers as Information Management Companies, available at: www.chartis.com (accessed 13 March 2019).

Kothman, I. and Faber, N. (2016), "How 3D printing technology changes the rules of the game: Insights from the construction sector", Journal of Manufacturing Technology Management, Emerald Group Publishing Limited, Vol. 27 No. 7, pp. 932-943.

Krejcar, O., Selamat, A., Svobodova, L., Soukal, I., Maresova, P., Javanmardi, E. and Hedvicakova, M. (2018), "Consequences of Industry 4.0 in Business and Economics", Economies, Multidisciplinary Digital Publishing Institute, Vol. 6 No. 3, p. 46.

Lam, S. (2014), "HKEx tech drive transforms Hong Kong's financial sector", ComputerwordHK, available at: https://www.cw.com.hk/it-hk/hkex-tech-drive-transforms-hong-kong-s-financial-sector.

Lee, J., Kao, H.A. and Yang, S. (2014), "Service innovation and smart analytics for Industry 4.0 and big data environment”, Procedia CIRP, Elsevier B.V., Vol. 16, pp. 3-8.

Lezzi, M., Lazoi, M. and Corallo, A. (2018), "Cybersecurity for Industry 4.0 in the current literature: A reference framework", Computers in Industry, Elsevier, Vol. 103, pp. 97-110.

Li, X., Wan, J., Lai, C.-F., Wang, S., Vasilakos, A. V. and Li, D. (2015), “A review of industrial wireless networks in the context of Industry 4.0”, Wireless Networks, Springer US, Vol. 23 No. 1, pp. $23-41$.

Lindstrom, S. (2017), Manufacturing and Distribution Industry Perspectives, available at: https://www.protiviti.com/US-en/insights/manufacturing-and-distribution-industry-perspectives-may-2017 (accessed 13 March 2019).

Lu, Y. (2017), "Industry 4.0: A survey on technologies, applications and open research issues", Journal of Industrial Information Integration, Vol. 6, pp. 1-10.

Madanapalle, A. (2017), "Big data and psychographic profiling helped Donald Trump win the US presidential election", TECH2, available at: https://www.firstpost.com/tech/news-analysis/big-data-and-psychographicprofiling-helped-donald-trump-win-the-us-presidential-election-3696847.html.

McKinsey \& Company. (2015), "Industry 4.0 How to Navigate Digitization of the Manufacturing Sector", Mckinsey Digital, available at: https://doi.org/10.1080/18811248.1966.9732270.

OliverWyman. (2016), Impact of Technology \& Industry Insights-MFG 4.0 Digital Industry, available at: https://www.rightplace.org/assets/img/uploads/resources/Events/2016/MFG-Tech-16/Joern-Buss-OliverWyman.pdf (accessed 12 March 2019).

Panda. (2017), "Chinese E-Commerce Giant Eyeing Digital Supply Chain to Create Competitive Advantage", Harvard Bussiness School, available at: https://rctom.hbs.org/submission/chinese-e-commerce-gianteyeing-digital-supply-chain-to-create-competitive-advantage/\#.

Pedone, G. and Mezgár, I. (2018), "Model similarity evidence and interoperability affinity in cloud-ready Industry 4.0 technologies", Computers in Industry, Elsevier, Vol. 100 No. February, pp. 278-286.

Pedram, A., Yusoff, N., Bin, Udoncy, O.E., Mahat, A.B., Pedram, P. and Babalola, A. (2017), "Integrated forward and reverse supply chain: A tire case study", Waste Management, Elsevier Ltd, Vol. 60, pp. $460-470$.

Pereira, G.B., Santos, A., de P.L. and Cleto, M.G. (2018), "Industry 4.0: glitter or gold? A systematic review", Brazilian Journal of Operations \& Production Management, Vol. 15 No. 2, pp. 247-253.

Piccarozzi, M., Aquilani, B. and Gatti, C. (2018), "Industry 4.0 in management studies: A systematic literature review”, Sustainability (Switzerland), Multidisciplinary Digital Publishing Institute, Vol. 10 No. 10, p. 3821.

Geissbauer, R., Vedso, J., S.S. (2016), "Industry 4 . 0 : Building the Digital Enterprise”, available at: https://doi.org/10.1080/01969722.2015.1007734.

RolandBerger. (2015), “The Industrie 4.0 Mastering the Transition Quantified, 2016”, available at: www.rolandberger.com.

Rüßmann, M., Lorenz, M., Gerbert, P., Waldner, M., Justus, J., Engel, P. and Harnisch, M. (2016), “Industrey 4.0 Future of Productivity", available at: https://doi.org/10.15713/ins.mmj.3.

Schenkel, R. (2016), "Industrie 4.0 Opportunity Discovery Workshop", available at: https://atos.net/wpcontent/uploads/2017/04/atos-industry-4-0-opportunity-discovery-workshop-brochure.pdf. (accessed 13 March 2019). 
Schreiber, B., Hoppe, W.-D. and Schoenefuss, B. (2016), "Future of Operations in the Digital World", available at: http://www.adlittle.com/sites/default/files/viewpoints/ADL_Future_of_Operations_in_the_digital_world.pdf (accessed 13 March 2019).

Singh Jain, A.D., Mehta, I., Mitra, J. and Agrawal, S. (2017), “Application of Big Data in Supply Chain Management”, Materials Today: Proceedings, Elsevier Ltd, Vol. 4 No. 2, pp. 1106-1115.

State Council of the People's Republic of China. (2015), "The state council issued a notice on 'made in China 2025"”, Www.Gov.Cn, available at: http://www.gov.cn/zhengce/content/2015-05/19/content_9784.htm.

The White House. (2011), "President Obama Launches Advanced Manufacturing Partnership", The White House Office of the Press Secretary, available at: https://obamawhitehouse.archives.gov/the-pressoffice/2011/06/24/president-obama-launches-advanced-manufacturing-partnership.

Tratz-Ryan, B., Hoeppe, A. and Basiliere, P. (2018), "Predicts 2018: Industrie 4.0 and Advanced Manufacturing", available at: https://doi.org/G00351698.

Valdivia, A., Luzón, M.V. and Herrera, F. (2017), "Sentiment Analysis in TripAdvisor", IEEE Intelligent Systems, Vol. 32 No. 4, pp. 72-77.

Vardhan Singh, H. and Berger, R. (2014), "Harsh Vardhan Singh”, available at: https://www.gita.org.in/Attachments/Reports/CII Roland Berger Industry 40.pdf (accessed 13 March 2019).

Varela, I.R. and Tjahjono, B. (2014), "Big data analytics in supply chain management: trends and related research", 6th International Conference on Operations and Supply Chain Management, Vol. 1 No. 1, pp. 2013-2014.

Wan, J., Tang, S., Shu, Z., Li, D., Wang, S., Imran, M. and Vasilakos, A. V. (2016), "Software-Defined Industrial Internet of Things in the Context of Industry 4.0”, IEEE Sensors Journal, Vol. 16 No. 20 , pp. 7373-7380.

Yiming Ma, Bee-Chung Chen and Deepak Agarwal, L.C. (2017), “How LinkedIn Makes Personalized Recommendations via Photon- ML Machine Learning tool”, KDnuggets, available at: https://www.kdnuggets.com/2017/10/linkedin-personalized-recommendations-photon-ml.html.

Zhou, K. (2015), "Industry 4.0 : Towards Future Industrial Opportunities and Challenges", 12th International Conference on Fuzzy Systems and Knowledge Discovery (FSKD), pp. 2147-2152.

\section{ACKNOWLEDGMENTS}

Thanks manpower and material support provided by the Industrial Engineering Laboratory (LGI) of CentraleSupelec, University of Paris Saclay. And we would like to extend my sincere gratitude to the funds provided by the China Scholarship Council to support our research. 